Journal of Applied Pharmaceutical Science Vol. 5 (12), pp. 021-028, December, 2015

Available online at http://www.japsonline.com

DOI: $10.7324 / J A P S .2015 .501204$

ISSN 2231-3354 (cc) EY-NC-SA

\title{
Synthesis of Novel Hydrogels based Poly(4-Hydroxyphenylazo-3-N- (4-hydroxyphenyl)maleimide) for Specific Colon Delivery of Chemotherapeutic Agent
}

\author{
P. Rama Subba Reddy ${ }^{1}$, K.S.V. Krishna Rao ${ }^{1,2^{*}}$, K. Madhusudana Rao ${ }^{3}$, N. Sivagangi Reddy ${ }^{1}$ \\ ${ }^{1}$ Polymer Biomaterial Design and Synthesis Laboratory, Department of Chemistry, Yogi Vemana University, Kadapa. Andhra Pradesh, India. \\ ${ }^{2}$ Department of Chemical Engineering and Material Science, Wayne State University, Detroit, MI, USA. ${ }^{3}$ Nano Information Materials Laboratory, \\ Department of Polymer Science and Engineering, Pusan National University, Busan, South Korea.
}

\author{
ARTICLE INFO \\ Article history: \\ Received on: 26/09/2015 \\ Revised on: 12/10/2015 \\ Accepted on: 02/11/2015 \\ Available online: 27/12/2015 \\ Key words: \\ Hydrogels, Azo compounds, \\ 5-Fluorouracil, Colon, Drug \\ Delivery
}

\begin{abstract}
In recent years azo functionalized polymeric hydrogels are very interesting; it is due to their promising applications in various fields especially in the colon drug delivery. 4-Hydroxyphenylazo-3-N-(4-hydroxyphenyl) maleimide (HPM) was synthesized and used for development of hydrogels by free radical polymerization with acrylamide (Am) and N,N-methylene bis acrylamide. Synthesized poly(Am-co-HPM) (PAH) hydrogels were used for encapsulation of 5-fluorouracil (5-FU) an anticancer drug. Structural, thermal, morphological and drug distribution of PAH hydrogels were characterized by Fourier transform infrared spectroscopy, scanning electron microscopy and X-ray diffraction techniques, respectively. Maximum percentage of encapsulation efficiency i.e. $78.25 \pm 1.3$ was observed for AZ1 PAH hydrogels. 5-FU release studies were performed by in vitro method in simulated gastro intestinal fluids ( $\mathrm{pH} 1.2 \&$ 7.4). To support the 5-FU release mechanism from PAH hydrogels, swelling and deswelling kinetics were studied in doubly distilled water.
\end{abstract}

\section{INTRODUCTION}

The specific colon delivery of drugs by various systems, such as prodrugs, polymeric drug and polymeric matrices has great interest in the recent years (Saffran et al., 1998; Kopeček and Kopečková, 1992; Tozer et al., 1991). Considering the requirement of specific colon drug delivery there are three approaches to reach the drug into the colon such as utilizing $\mathrm{pH}$ changes in the gastrointestinal tract (GIT) (Ashford et al., 1993; Kuethe, 1992), timed release capsules (Davis et al., 1986; Sudhakar et al., 2013), and polymeric carriers degraded by

\footnotetext{
* Corresponding Author

Dr. K.S.V. Krishna Rao, UGC-RAMAN Postdoctoral Fellow, Department of Chemical Engineering, Wayne state University, Detroit, USA.

Assistant Professor, Department of Chemistry, Yogi Vemana University, Kadapa, A.P., Andhra Pradesh, India- 516003.

Phone: +1 313246 7019, E-mail: ksvkr@yogivemanauniversity.ac.in
}

the microflora located in the colon (Brown et al., 1983). The mechanism of these colon-specific drug delivery systems is presumed to take place due to enzymatic cleavage by the normal colonic microflora. The rich microflora of the human colon is responsible for the conversion of laxatives such as suhstine and sennosides to active therapeutics. There are only a few studies performed on polymeric systems that could carry a variety of drugs to the colon. A more universal approach to utilize bacterial degradation of the azo bond to achieve specific release has been the synthesis of a polymer suitable for coating (Saffran et al., 1986; Prabhakar et al., 2013), and the use of hydrogels with azoaromatic cross-links (Brondsted and Kopecek, 1992; Mallikarjuna et al., 2013).

To reduce the side effects and increasing bioavailability, colon formulation approach has been used (Philip et al.,2008). The specific site targeted drug delivery to the colon is most important in the treatment of colonic diseases such as inflammatory bowel diseases, irritable bowel syndrome and colon cancer. 
Hence it is essential to enhance the release rate of drug and absorb drug at colon for chemotherapy. Other potential applications of colonic delivery include chronotherapy, prophylaxis of colon cancer and treatment of nicotine addiction (Davis, 1990). The most critical challenge in such drug delivery approach is to preserve the formulation and also preserve the drug from degradation, release and/or absorption in the upper portion of the GIT (Ashford and Fell, 1994; Chandra Sekhar et al., 2014).

To achieve successful colon targeted drug delivery, a formulation need to produce controlled release in the proximal colon. The drug formulations such as therapeutic proteins and peptides which are susceptible to chemical and enzymatic degradation in the upper GIT are suitable for colonic delivery (Luck and Crabb, 2000).

In the present investigation attempts were made to develop novel azo functionalized polymeric hydrogels from 4hydroxyphenylazo-3-N-(4-hydroxyphenyl) maleimide (HPM) and acryl amide (Am) free radical polymerization for colon drug delivery. This poly(Am-co-HPM) hydrogels were characterized by FTIR, DSC, XRD and SEM. The in vitro release studies of the incorporated 5-fluorouracil (5-FU) were carried out in simulated gastric and intestinal fluids.

\section{MATERIALS AND METHODS}

\section{Materials}

Acrylamide (Am), Potassium persulphate (KPS), 4amino phenol and maleic anhydride purchased from s.d. Fine chemicals. N,N-methylene-bis-acrylamide (MBA), 5-Fluorouracil (5-FU), were purchased from Aldrich chemicals Mumbai, India. All other chemicals were analytical grade and were used as received without further purification. 4-hydroxyphenylazo-3-N-(4hydroxyphenyl) maleimide was synthesized as reported in literature (Mohammed and Mustapha, 2010). Double distilled (DD) water was used throughout the experiments.

\section{Preparation of PAH hydrogels}

poly(Am-co-HPM) hydrogels were prepared by free radical copolymerization. Monomers (Am and HPM) were dissolved in $4 \mathrm{~mL}$ of distilled water, to this solution $1 \mathrm{~mL}$ of crosslinking agent ( $2 \mathrm{wt} \%, \mathrm{MBA}), 1 \mathrm{~mL}$ of potassium per sulfate solution (5 wt \%)

The free-radical polymerization was carried out in a 50 $\mathrm{mL}$ beaker maintained at $60^{\circ} \mathrm{C}$ temperature in order to complete matrix formation. The schematics of chemical reaction of $\mathrm{PAH}$ hydrogel has given in Scheme I. The digital photographs of synthesized PAH hydrogels are shown in Figure 1.

\section{Swelling studies of PAH hydrogels}

The percentage of swelling is the most important parameter for characterization of hydrogels (Omidian et al., 1994). Swelling and deswelling kinetics of the PAH hydrogels were studied in DD water by mass measurements at $37^{\circ} \mathrm{C}$. The percentage of swelling ratio $(\% \mathrm{SR})$ and equilibrium swelling ratio (\%ESR) was calculated by following Equation.

$$
\% \text { Swelling ratio of } \mathrm{PAH} \text { hydrogels }=\left(\frac{\mathrm{m}_{t}-\mathrm{m}_{\mathrm{d}}}{\mathrm{m}_{\mathrm{d}}}\right) \times 100
$$

Where $m_{t}$ and $m_{d}$ are weight of swollen PAH hydrogels for a given time $t$ and dried PAH hydrogels, respectively.

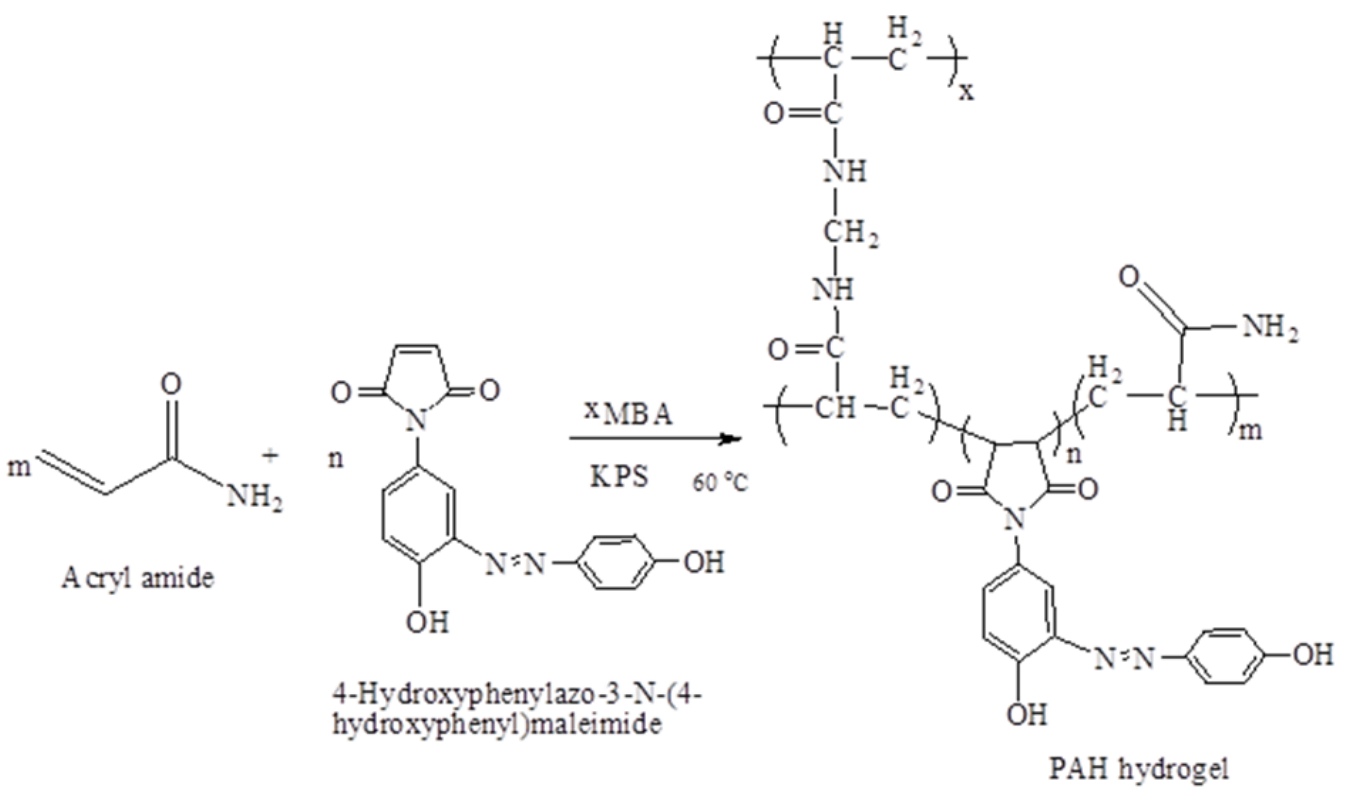

Scheme I. Schematic representation of PAH hydrogels. 


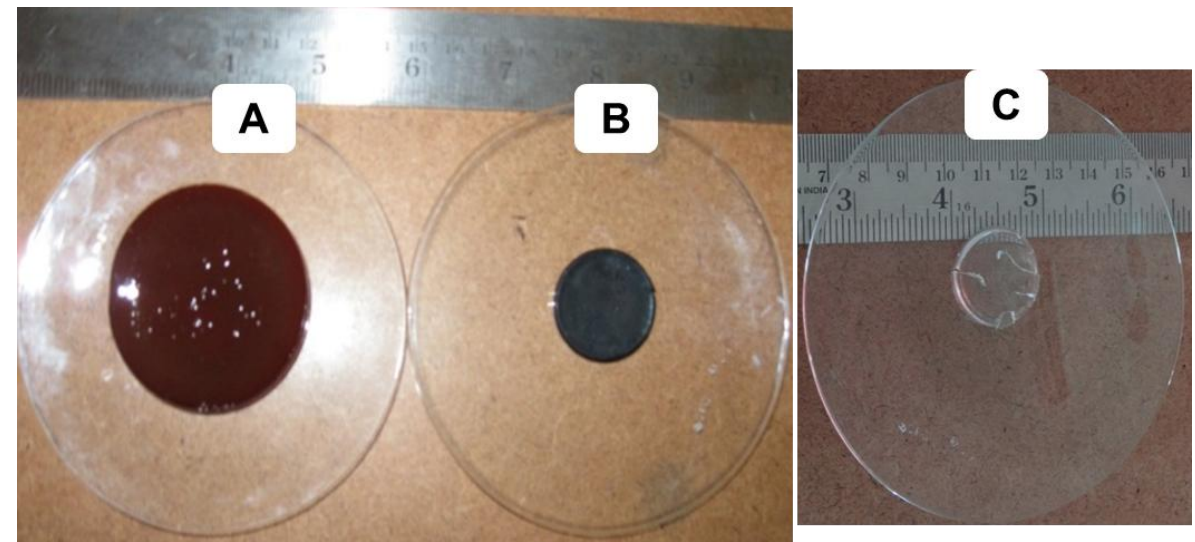

Fig. 1: A digital photograph of (A) swollen, (B) dried poly(Am-co-HPM) hydrogels and (C) poly(Am) dried hydrogels

Table 1: Results of \% encapsulation efficiency of PAH hydrogels loaded with 5-FU and Release kinetic parameters of different formulations

\begin{tabular}{lcccccccc}
\hline Code & Am $(\mathbf{g})$ & HPM $(\mathbf{g})$ & MBA $(\mathbf{m l})$ & APS $(\mathbf{m l})$ & $\boldsymbol{\% E E}$ & $\boldsymbol{n}$ & $\boldsymbol{r}^{2}$ & $\boldsymbol{k}$ \\
\hline AZ1 & 1 & 0.5 & 1 & 1 & $78.25 \pm 1.3$ & 0.473 & 0.987 & 0.4819 \\
AZ2 & 1 & 0.5 & 2 & 1 & $63.76 \pm 1.8$ & 0.672 & 0.986 & 0.1276 \\
AZ3 & 1 & 0.25 & 1 & 1 & $62.09 \pm 0.9$ & 0.745 & 0.979 & 0.4415 \\
AZ4 & 1 & 0.1 & 1 & 1 & $53.87 \pm 2.1$ & 0.672 & 0.986 \\
AZ5 & 1 & 0.5 & 3 & 1 & $42.03 \pm 1.1$ & 0.1288 & 0.653 & 0.948 \\
\hline
\end{tabular}

\section{5-FU loading and encapsulation efficiency of PAH hydrogels}

The anticancer drug 5-FU loaded into PAH hydrogels by equilibrium swelling method. The known concentration of 5-FU drug solution was prepared and allowed to swell the $\mathrm{PAH}$ hydrogels for $24 \mathrm{~h}$ at $37^{\circ} \mathrm{C}$. The 5 -FU loaded PAH hydrogels were placed in $10 \mathrm{~mL}$ of buffer solution and stirred vigorously for $24 \mathrm{~h}$ to extract 5-FU drug from the PAH hydrogels. The solution was filtered and assayed by UV spectrophotometer (LAB INDIA, UV3092 ) at fixed $\lambda_{\max }$ value of $270 \mathrm{~nm}$. The results of \% 5-FU loading and encapsulation efficiency (\% EE) were calculated using Eqs. (2) and (3) respectively. These data are compiled in Tables 1, respectively.

$\% 5$ - FU loading $=\left(\frac{\text { Amount of } 5-\mathrm{FU} \text { in PAH hydrogels }}{\text { Amount of PAH hydrogels }}\right) \times 100.2$

$\% 5$-FU encapsulation efficiency $=\left(\frac{\text { Actual 5-FU PAH loading }}{\text { Theoretical 5-FU PAH loading }}\right) \times 100 \quad \ldots 3$

\section{In-vitro release study of PAH hydrogels}

Dissolution was carried out using the fully automated dissolution system (DS 8000, LAB INDIA) equipped with eight baskets. Dissolution rates were measured at $37^{\circ} \mathrm{C}$ under $100 \mathrm{rpm}$ speed. Drug release from the PAH hydrogel was studied in simulated gastric fluid $(\mathrm{pH}$ 1.2) and simulated intestinal fluid $(\mathrm{pH}$ 7.4) at $37^{\circ} \mathrm{C}$. At periodic intervals of time, aliquot samples were pipetted out and assayed using LAB INDIA, UV-3092, UV-Vis spectrophotometer. After each sampling an equal volume of fresh buffer solution was added to the release medium.

\section{Characterization}

The chemical structure of PAH hydrogels were analyzed by Fourier transform infrared spectroscopy (FTIR) using Perkin
Elmer, Spectrum Two model. The PAH hydrogels were finely ground with $\mathrm{KBr}$ to prepare the pellets under a hydraulic pressure of 392.2 dynes $/ \mathrm{m}^{2}$ and spectra were scanned between 4000 and $500 \mathrm{~cm}^{-1}$. Differential scanning calorimetry (DSC) curves of the pristine 5-FU, placebo $\mathrm{PAH}$ hydrogels and 5-FU loaded $\mathrm{PAH}$ hydrogels were recorded using DSC 200F3 Maia. The analysis was performed by heating the samples at the rate of $10{ }^{\circ} \mathrm{K} / \mathrm{min}$ under nitrogen atmosphere and temperature range between 0 $580^{\circ} \mathrm{C}$.

The X-ray diffractograms of pure 5-FU, PAH hydrogels and 5-FU loaded PAH hydrogels were recorded on X-ray diffractometer (Philips, PW1830) equipped with a Ni-filtered $\mathrm{CuK} \alpha$ radiation $\left(\lambda=1.5418 \mathrm{~A}^{\circ}\right)$. The PAH hydrogels were mounted on a sample holder and XRD scans were recorded in the $2 \theta$ range of $0-80^{\circ}$ at the speed of $5^{\circ} / \mathrm{min}$ to estimate the crystallinity of the PAH hydrogels.

The morphological characteristics of the PAH hydrogels were studied using scanning electron microscopy (model: MIRAIITESCAN).

\section{RESULTS AND DISCUSSION}

\section{Characterisation of 4-Hydroxyphenylazo-3-N-(4- hydroxyphenyl)maleimide}

The FTIR and ${ }^{1} \mathrm{H}-\mathrm{NMR}$ spectrum of 4Hydroxyphenylazo-3-N-(4-hydroxyphenyl)maleimide is shown in Figure 2 and 3.; Color: yellow brown; yield: 78\%; melting point: 215-218 ${ }^{\circ} \mathrm{C}$; FTIR (KBr disc): $3,310 \mathrm{~cm}^{-1}(\mathrm{O}-\mathrm{H}), 3,170 \mathrm{~cm}^{-1}$ $(\mathrm{HC}=\mathrm{CH}), 1,715 \mathrm{~cm}^{-1}(\mathrm{C}=\mathrm{O}), 1,610 \mathrm{~cm}^{-1}$ (aromatic ring) and 1,575 $\mathrm{cm}^{-1}(\mathrm{~N}=\mathrm{N}), 830 \mathrm{~cm}^{-1}$ and $716 \mathrm{~cm}^{-1} ;{ }^{1} \mathrm{H}-\mathrm{NMR}$ (D6 DMSO): $7.17-$ 7.57 (aromatic), 6.96-7.21 ( $\mathrm{HC}=\mathrm{CH}$ of maleimide), 6.31-6.51 $(\mathrm{HC}=\mathrm{CH}) \mathrm{ppm}$. 


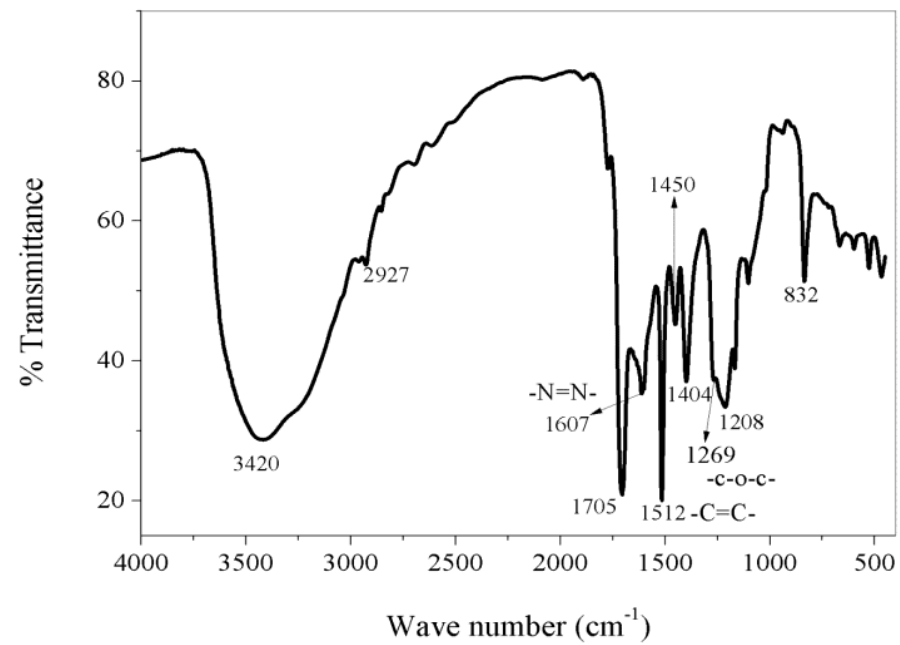

Fig. 2 FTIR Spectra of 4-hydroxyphenylazo-3-N-(4-hydroxyphenyl) maleimide.
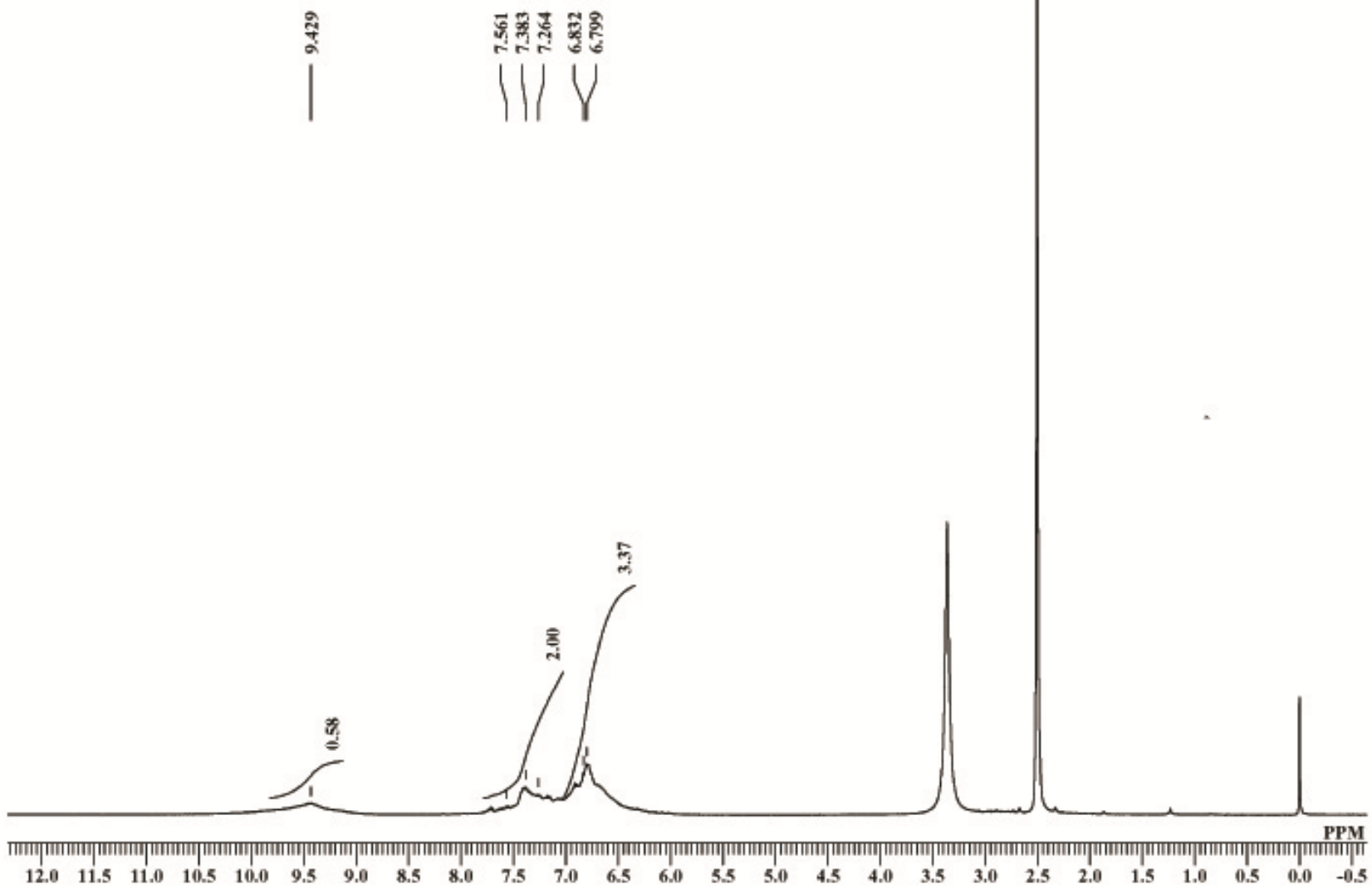

Fig. $3{ }^{1} \mathrm{H}$ NMR spectra of 4-hydroxyphenylazo-3-N-(4-hydroxyphenyl) maleimide.

\section{FTIR Spectra analysis of PAH hydrogels}

The FTIR spectra of PAH hydrogels of AZ1 formulation, 5-FU loaded AZ1 and pure 5-FU drug and the spectra of the same presented in figure 4 . From figure $4 \mathrm{a}$, pure 5 -FU shows the characteristic peak at $3125 \mathrm{~cm}^{-1}$ for N-H stretching (free) and also peaks at $1729,1648,1247$, and $1175 \mathrm{~cm}^{-1}$ for carbonyl stretching $(\mathrm{C}=\mathrm{O})$, C-N stretching, C-F stretching and $\mathrm{C}-\mathrm{O}$ stretching vibrations appear in pure 5-FU also in drug loaded hydrogel respectively. The FTIR spectra of AZ1 hydrogels in figure 4 (b), the $\mathrm{N}-\mathrm{H}$ stretching vibration in methylene bis(acrylamide) appear at 3420 or amide groups of acrylamide in hydrogels appear at 1660 $\mathrm{cm}^{-1}$ and hydroxyl group merged in $3420 \mathrm{~cm}^{-1}$ region. The peat for alkene group $(\mathrm{HC}=\mathrm{CH})$ appear at $3030 \mathrm{~cm}^{-1}$. The presence of the azo $(\mathrm{N}=\mathrm{N})$ group band in $1594 \mathrm{~cm}^{-1}$ range confirmed the HPM copolymerized with acrylamide and formation of PAH hydrogels. In the case of pure 5-FU the bands at $3130,1245 \mathrm{~cm}^{-1}$ gives information of N-H stretching (free) and -C-F band after drug loading some of the bands disappear and $\mathrm{N}-\mathrm{H}$ stretching (free) 
appear at same, $-\mathrm{C}-\mathrm{F}$ band appear at $1245 \mathrm{~cm}^{-1}$. This indicate that the 5-FU is molecularly dispersed in to the PAH hydrogels. The interactions between functional groups in interpenetrating polymer networks are great potential use in pharmaceutical preparations, especially in drug delivery systems.

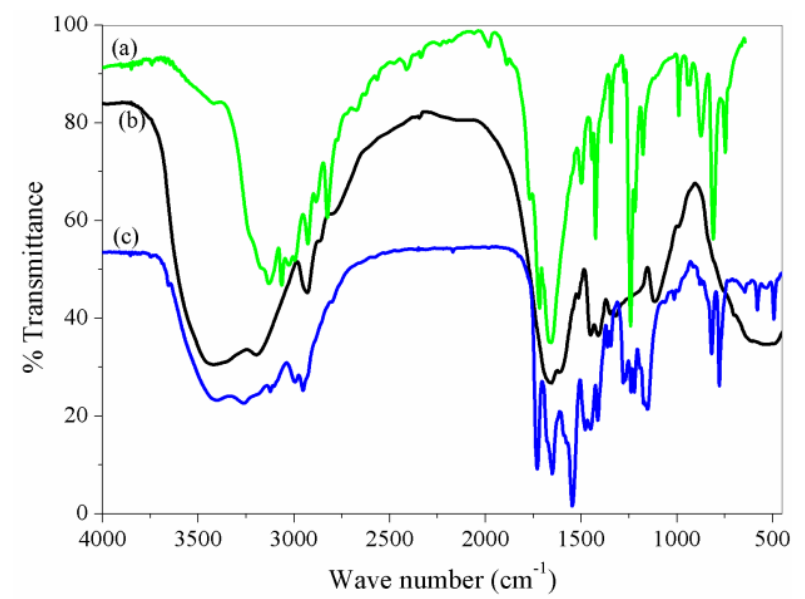

Fig. 4: FT-IR spectra of (a) pure 5-FU (b) PAH hydrogel (c) drug loaded PAH hydrogels (sample AZ1).

\section{Differential Scanning Calorimetry (DSC)}

The DSC thermograms of pure 5-FU, placebo PAH and drug loaded PAH hydrogels is as depicted in figure 5. The DSC of pure 5-FU showed a sharp melting endotherm was observed at 282 ${ }^{\circ} \mathrm{C}$ followed by decomposition those reported previously (Rama Subba Reddy et al., 2014; Chandra Sekhar et al., 2014). The DSC of PAH hydrogels shows three staged weight loss.

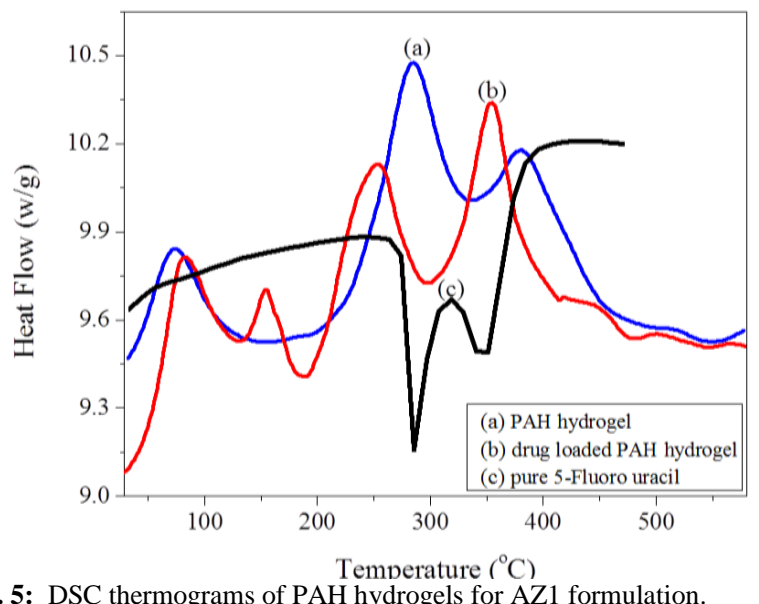

Fig. 5: DSC thermograms of PAH hydrogels for AZ1 formulation.

The melting exotherms were observed at 73.04, $285.40 \&$ $380.16^{\circ} \mathrm{C}$ and two melting endotherms were observed at 157.30 , $336.52^{\circ} \mathrm{C}$. The broad endothermic peak was observed around $150^{\circ} \mathrm{C}$ can be explained by the evaporation of water from the hydrogels. The DSC analysis of 5-FU loaded PAH hydrogels showed three melting endotherms at $130.22,187.02$ and $296.92^{\circ} \mathrm{C}$. The first endotherm corresponds to melting of the acrylamide chains, for 4-hydroxyphenylazo-3-N-(4-hydroxyphenyl)maleimide melting endotherms at $187.02^{\circ} \mathrm{C}$ and we observed the DSC thermogram of $5-\mathrm{FU}$ drug at $282^{\circ} \mathrm{C}$ had changed in the DSC thermogram of the 5-FU loaded $\mathrm{PAH}$ hydrogel at $296.92^{\circ} \mathrm{C}$ indicating that the 5-FU drug had been successfully loaded in the hydrophobic core of the hydrogel network.

\section{X-ray diffraction analysis (XRD)}

XRD diffractograms of PAH hydrogel, 5-FU loaded $\mathrm{PAH}$ hydrogel and pristine 5-FU are displayed in Figure 6, indicates that the crystalline nature of the drug before and after encapsulation in the hydrogel. The 5-FU has shown characteristic intense peak at $2 \theta$ of $29 \circ$ due to its crystalline nature. However, these peaks have disappeared in 5-FU loaded hydrogels, since molecular level dispersion in the hydrogel network, as no crystals were found in the 5-FU loaded hydrogel network.

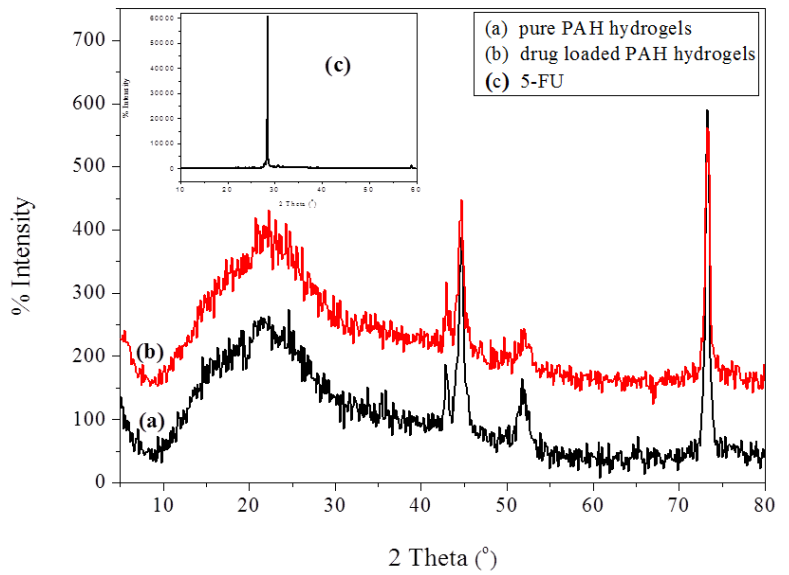

Fig. 6: XRD pattern of the (A) pure 5-FU, (B) PAH hydrogel and (C) drug loaded PAH hydrogels for AZ1 formulation.
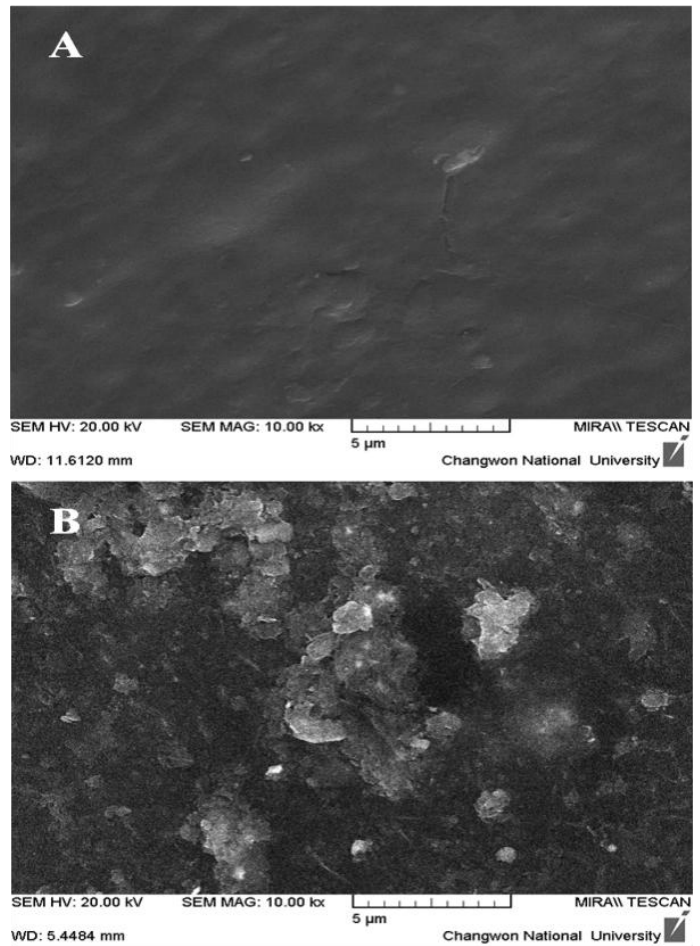

Fig. 7: Scanning electron microscopy images of (A) AZ1 PAH hydrogels and (B) AZ1 PAH hydrogels after drug release. 


\section{Scanning Electron Microscopy (SEM)}

SEM studies were performed for PAH hydrogel of AZ1 formulation, before and after drug release the SEM images are presented in figure 7A and 7B.The SEM image of pure AZ1 shows smooth surfaces and less pore size but in the case of AZ1 hydrogels after drug release in the alkaline environment; the surface appeared rough having pore size. The hydrogel is exposed to $\mathrm{pH}$ environment the size of pore was affected this indicates that the hydrogel have a good $\mathrm{pH}$-responsibility, it is useful for colon drug delivery.

\section{Swelling studies}

The swelling and deswelling kinetic studies of the PAH hydrogels with different HPM and MBA concentrations are shown in figure $8 \mathrm{~A}$. The swelling data shows that the rate of swelling is increased with increasing amount of HPM content in the PAH hydrogel matrix this is due to hydrophilic nature of hydroxyl and amide functional group. While in the case of AZ1, AZ2 and AZ5 formulations the swelling ratio decreases due to increasing cross linker content (MBA) from $0.0013 \mathrm{~mol}$ to $0.0038 \mathrm{~mol}$. The crosslinked PAH hydrogels swelled to about $80 \%$ at equilibrium, reached after $42 \mathrm{~h}$. The percentage swelling at equilibrium increased with the increase in $\mathrm{pH}$ from acid to alkaline range. The same trend follows in the case of deswelling kinetics (figure8B) of PAH hydrogels.

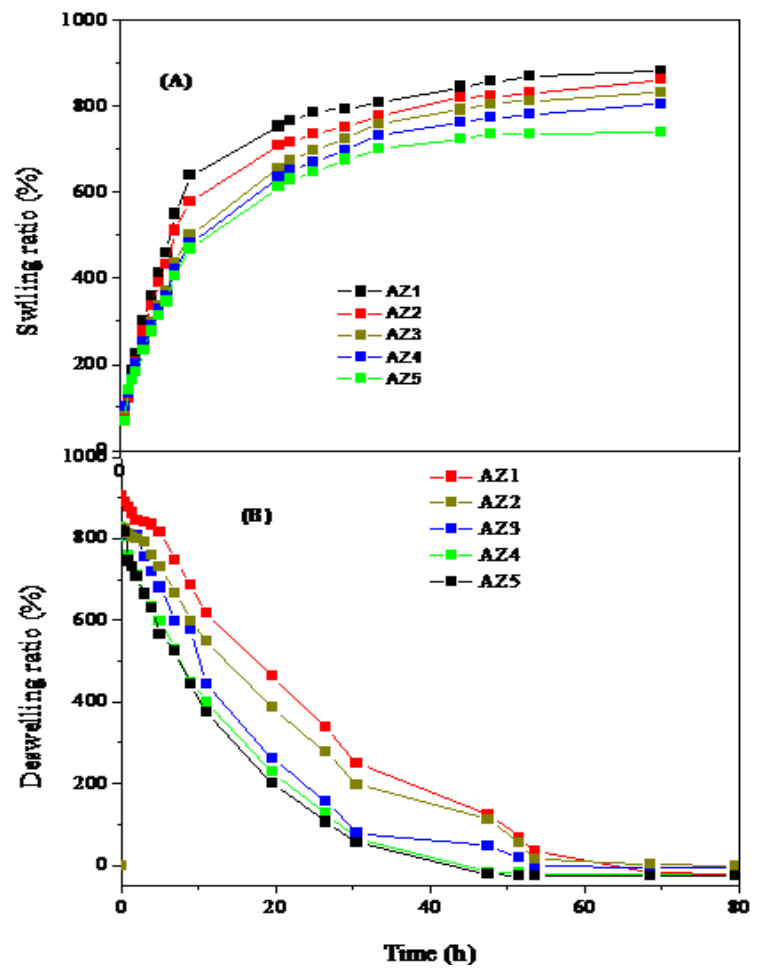

Fig. 8: Swelling (A) and deswelling (B) ratio of poly(Am-co-HPM) hydrogels

\section{In vitro release kinetic studies}

Figure 9a. shows the in vitro release profiles of 5-FU from the $\mathrm{PAH}$ hydrogels in $\mathrm{pH}=1.2$. There was about $40 \%$ drug release with in $3 \mathrm{~h}$ and about $42 \%$ release at the end of $5 \mathrm{~h}$ from
AZ1 hydrogel. In the case of AZ3 hydrogel there was about 20\% release in $3 \mathrm{~h}$ and $30 \%$ drug release after $5 \mathrm{~h}$ where as it was $10 \%$ and $18 \%$ in the case of AZ4 hydrogels at the end of $3 \mathrm{~h}$ and $5 \mathrm{~h}$, respectively.

In the first $3 \mathrm{~h}$ there was an initial burst release and this was followed by near zero order patterns up to $16 \mathrm{~h}$. The cumulative release profiles of 5-FU from the PAH hydrogels in $\mathrm{pH}$ $=7.4$ phosphate buffer are shown in figure 9b. The AZ1 hydrogels released about $40 \%$ of $5-\mathrm{FU}$ in $3 \mathrm{~h}$ and about $46 \%$ of $5-\mathrm{FU}$ entrapped in $5 \mathrm{~h}$. The drug released from AZ3 hydrogels was about $19 \%$ in $3 \mathrm{~h}$ and $29 \%$ after $5 \mathrm{~h}$, whereas it was $10 \%$ in $3 \mathrm{~h}$ and $18 \%$ at the end of $5 \mathrm{~h}$ from AZ4 hydrogels.
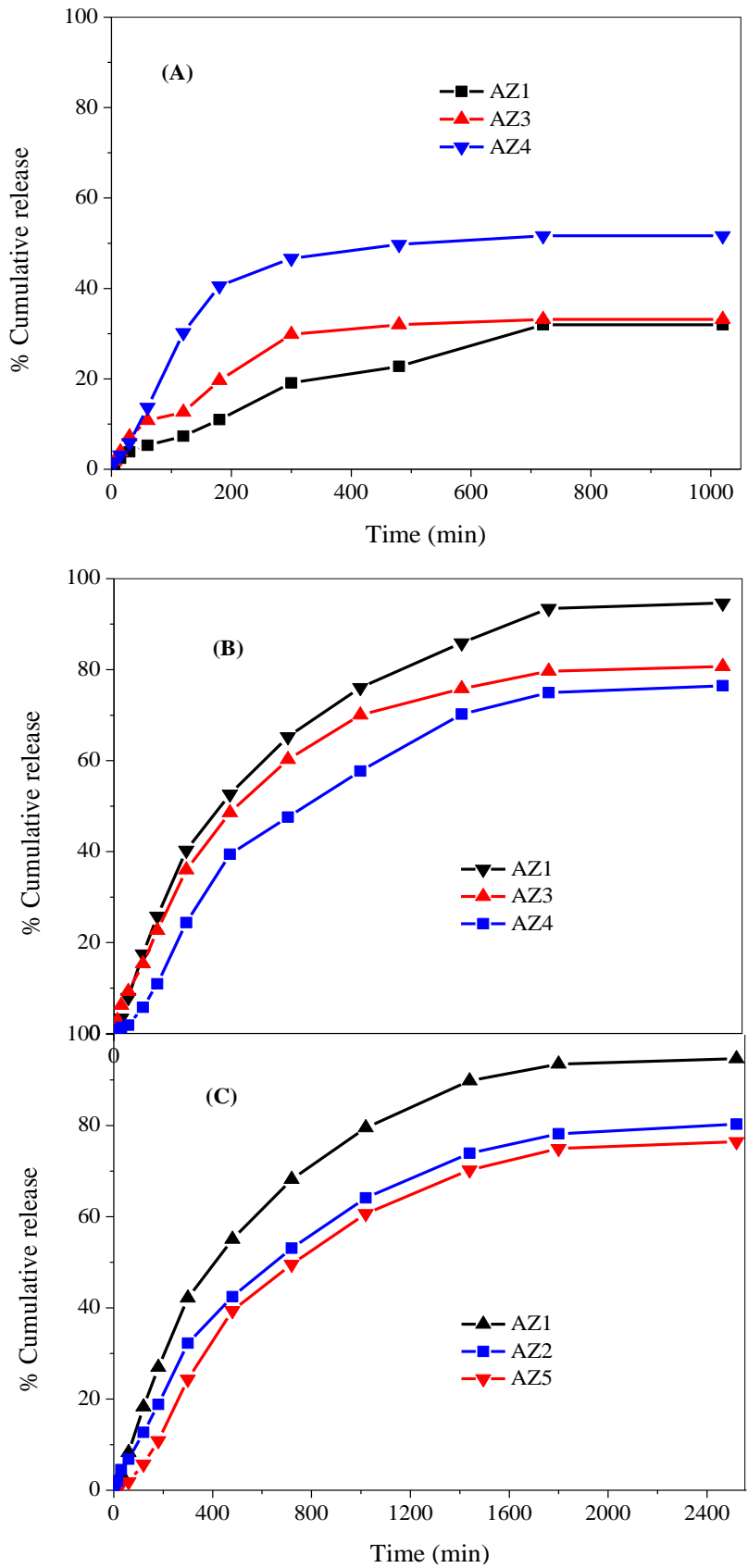

Fig. 9: \% Cumulative release of monomer variation in (a) $\mathrm{pH} 1.2$ (b) $\mathrm{pH} 7.4$ and (c) MBA variation of poly(Am-co-HPM) hydrogels in $\mathrm{pH}$ 7.4. 
The cumulative release of 5-FU influenced by MBA (cross linker) concentrations and the release profiles are shown in figure 9c. The AZ1 hydrogels released about $27 \%$ of 5 -FU in $3 \mathrm{~h}$ and about $43 \%$ of 5 -FU released in $5 \mathrm{~h}$. In the case of AZ2 hydrogels $18 \%$ drug release in $3 \mathrm{~h}$ and $33 \%$ release in $5 \mathrm{~h}$. The AZ5 hydrogels only $10 \%$ in $3 \mathrm{~h}$ and $25 \%$ drug release in $5 \mathrm{~h}$. This indicates that the cross linker concentration increases rigidness of the matrix increases and the free volume available for penetrant diffusion decreases. As the concentration of MBA increases from $0.0013 \mathrm{~mol}$ to $0.0038 \mathrm{~mol}$, the mobility of the polymeric chains decreases dramatically.

The kinetics of the synthesized $\mathrm{PAH}$ hydrogels was studied at $37^{\circ} \mathrm{C}$, in aqueous buffer solutions of $\mathrm{pH}=1.2$ and 7.4. The total buffer concentration was maintained $0.05 \mathrm{M}$, and the ionic strength $(\mathrm{m})$ is 0.5 for phosphate buffer. The release of 5-FU was monitored by UV-Vis spectrophotometer and using above data $\%$ cumulative release calculated and fitted into the following peppas equation ( $\mathrm{Li}$ et al., 2006). The diffusion parameters $\mathrm{k}, \mathrm{n}$ and $\mathrm{r}^{2}$ value were calculated and presented in Table 1.

$$
\frac{m_{t}}{m_{\infty}}=k t^{n}
$$

Where $m_{t}$ and $m_{\infty}$ is the amount of drug released at time $t$, and the total drug release at equilibrium in the PAH hydrogels, $m_{t} / m_{\infty}$ is the fractional release of the drug, $\mathrm{k}$ is the release rate constant and $\mathrm{n}$ is the release exponent, indicating the mechanism of type of drug release. The release exponent, release rate constant and correlation coefficients for the PAH hydrogels containing 5-FU are presented in Table 1. The type of release mechanism is given by the $n$ value in peppas equation, where $n \leq 0.5$ indicates Fickian diffusion; while $0.5<n<1$ indicates non-Fickian diffusion (anomalous mass transfer). Based on release data the highest correlation coefficient was observed for AZ1 hydrogels this indicates that 5-FU is released from $\mathrm{PAH}$ hydrogels by Fickian diffusion that means diffusion rate of the $\mathrm{PAH}$ hydrogels is much lower than the relaxation time. At the same time we demonstrate based on peppas equation the release exponent is 0.47 or very close to 0.5 .

\section{Mechanism of 5-FU Release}

The 5-FU was entrapped into the PAH hydrogels and the action of 5-FU release was observed in $\mathrm{pH} 1.2$ and 7.4 phosphate buffer media. The percent (\%) of swelling ratio of $\mathrm{PAH}$ hydrogel is less in the region of $\mathrm{pH} \mathrm{1.2,} \mathrm{while} \mathrm{in} \mathrm{the} \mathrm{case} \mathrm{of} \mathrm{pH} 7.4$ the $\%$ of swelling ratio is more due to hydrophilic nature of PAH networks present in the hydrogel. Based on the swelling ratio, the cumulative release of 5-FU in PAH hydrogels follows and when the drug loaded PAH hydrogel reached the stomach, the hydrogels will be exposed to acidic environment $(\mathrm{pH}=1.2)$ and the release of 5-FU from PAH hydrogels very low, this is due to the release of the surface entrapped 5-FU drug only. The cumulative release of 5-FU from PAH hydrogels in $\mathrm{pH} 7.4$ increases slowly due to alkaline environment present in the large intestine and also contributes to the swelling of PAH hydrogels and the azo bond will be accessible for cleavage. The swollen hydrogels are easy to cleaving the azo bond and causes release of the 5-FU in the colon by loosening the PAH hydrogel matrices.

\section{CONCLUSION}

The poly(Am-co-HPM) hydrogels containing azo aromatic copolymers were developed for colon targeting by simple free radical polymerization method and were cross-linked with N,N-methylene bis acrylamide. The 5-FU release rate decreases with increasing MBA concentration in the PAH hydrogels. The slowest \% cumulative release was obtained for the most viscous cross-linked AZ5 PAH hydrogels. The rate of 5-FU release can be controlled by the HPM concentration, and crosslinking agent. The PAH hydrogels were characterized by FTIR, DSC, XRD and SEM. The percentage of swelling studies were carried out in deionized water and Invitro release studies of 5-FU entrapped in the hydrogels were carried out in SGF and SIF. The maximum encapsulation efficiency of 5 -FU is $78.25 \%$ and the release of 5FU from PAH hydrogels is more in alkaline environment when compared to acidic media.

\section{ACKNOWLEDGEMENTS}

Authors are highly thankful to the Department of Science and technology (DST), New Delhi, India, (DST No.SR/FT/CS047/2009) for a financial support. The author K.S.V.K. Rao also thanks to UGC MRP. F.No. 42-257/2013 (SR) for partial financial support.

\section{REFERENCES}

Ashford M, Fell JT, Attwood D, Wood head PJ. An-vitro investigation into the suitability of $\mathrm{pH}$ dependent polymers for colonic targeting. International Journal of Pharmaceutics, 1993; 91(2-3): 241-245.

Ashford M, Fell JT. Targeting drugs to the colon: Delivery systems for oral administration. J Drug Target, 1994; 2:241-258.

Brondsted H, Kopecek J. Hydrogels for site-specific drug delivery to the colon: in vitro and in vivo degradation. Pharmaceutical Research, 1992; 9(12):1540-1545.

Brown JP, Mc Garraugh GV, Parkinson TM, Wingard RE Jr, Oderdonk AB. A polymeric drug for treatment of inflammatory bowel disease. Journal of Medicinal Chemistry, 1983; 26(9): 1300-1307.

Chandra Sekhar E, Krishna Rao KSV, Madhu Sudana Rao K, Eswaramma S, Ramesh Raju R., Development of Gelatin-Lignosulfonic acid Blend Microspheres for Controlled Release of an Anti-Malarial Drug (Pyronaridine). Indian Journal of Advances in Chemical Science, 2014; 3: 25-32.

Davis SS, Hardy JG, Fara JW. Transit of pharmaceutical dosage forms through the small intestine. Gut, 1986; 27: 886-892.

Davis SS. Overcoming barriers to the oral administration of peptide drugs. Trends in Pharmacological Sciences, 1990; 11:353-355.

Dolan, T.F., Humphrey, M.J., Nichols, D.J, US20006106864 (2000). Philip AK, Dubey RK, Pathak K. Optimizing delivery of furbiprofen to the colon using a targeted prodrug approach. J Pharm Pharmacol, 2008, 60, 607-613.

E. Chandra Sekhar, K. Madhusudana Rao, S. Eswaramma, K. S. V. Krishna Rao, R. Ramesh Raju, (2014) Development of sodium alginate/(lignosulfonicacid-g-acrylamide) IPN micro beads for controlled release of an anti-malarial drug. Indian Journal of Advances in Chemical Science, 2(3): 228-237.

Kopeček J, Kopečková P. 1992. N-(2-Hydroxypropyl) methacrylamide Copolymers for Colon Specific Drug Delivery in: Oral 
Colon-Specific Delivery. Friend DR, Ed., CRC Press, Boca Raton, Florida, 189-211.

Kuethe DO, Augenstein DC, Gresser JD, Wise DL. Design of capsules that burst at predetermined times by dialysis. Journal of Control Release, 1992; 18(2): 159-164.

Li X, Wu W, Wang J, Duan Y. The swelling behavior and network parameters of guar gum/poly(acrylic acid) semi-interpenetrating polymer network hydrogels. Carbohydrate Polymers, 2006; 66: 473-479.

Luck M, Crabb J. US20006074689 (2000).

Mallikarjuna B, Madhusudana Rao K, Sudhakar P, Chowdoji Rao K, Subha MCS. Chitosan based biodegradable hydrogel microspheres for controlled release of an anti HIV drug. Indian Journal of Advances in Chemical Science, 2013; 1: 144-151.

Mohammed IA, Mustapha A. Synthesis of New Azo Compounds Based on N-(4-Hydroxypheneyl)maleimide and N-(4Methylpheneyl)maleimide. Molecules, 2010; 15(10):7498-7508.

Omidian H, Hashemi SA, Askari F, Nafisi S. Swelling and Crosslink Density Measurements for Hydro-gels. Iranian Journal of Polymer Science and Technology, 1994; 3(2): 115-119.

Prabhakar MN, Sajankumarji Rao U, Kumara Babu P, Subha MCS, Chowdoji Rao K. Interpenetrating polymer network hydrogel membranes of PLA and SA for control release of penicillamine drug. Indian Journal of Advances in Chemical Science, 2013; 1: 240-249.

Rama Subba Reddy P, Madhusudana Rao K, Krishna Rao KSV, Yury Shchipunov, Chang-Sik Ha. Synthesis of Alginate Based Silver Nanocomposite Hydrogels for Biomedical Applications. Macromolecular Research, 2014; 22: 832-842.
Saffran M, Bedra C, Kumar GS, Neckers DC. Vasopressin: A model for the study of effects of additives on the oral and rectal administration of peptide drugs. Journal of Pharmaceutical Sciences, 1988; 77: 33-38.

Saffran M, Kumar GS, Savariar C, Burnham JC, Williams F, Neckers DC. A new approach to the oral administration of insulin and other peptide drugs. Science, 1986; 233(4768):1081-1084.

Sudhakar P, Madhusudana Rao K, Siraj S, Chandra Babu A, Chowdoji Rao K, Subha MCS. Controlled release of hypertensive drug from $\mathrm{pH} /$ thermo responsive polymeric microbeads. Indian Journal of Advances in Chemical Science, 2013; 2: 50-56.

Tozer TN, Rigod J, McLeod A.D, Gungon R, Hoag MK, Friend DR. Colon specific delivery of dexamethasone from a glucoside prodrug in the guinea pig. Pharmaceutical Research, 1991; 8(4): 445-454.

\section{How to cite this article:}

Reddy PRS, Krishna Rao KSV, Rao KM, Reddy NS. Synthesis of Novel Hydrogels based Poly (4-Hydroxyphenylazo-3-N-(4hydroxyphenyl)maleimide) for Specific Colon Delivery of Chemotherapeutic Agent. J App Pharm Sci, 2015; 5 (12): 021-028. 